\title{
Dendrite Refinement and Improved Mechanical Properties of SiC/ TiC/Al Hybrid Nanocomposites
}

\author{
Hui Xie iD and Jinze Lv \\ Avic China Helicopter Research and Development Institute, Jiangxi, Jingdezhen 333001, China \\ Correspondence should be addressed to Hui Xie; huixie1020@163.com
}

Received 16 January 2022; Revised 28 January 2022; Accepted 2 February 2022; Published 3 March 2022

Academic Editor: Dimitrios E. Manolakos

Copyright (c) 2022 Hui Xie and Jinze Lv. This is an open access article distributed under the Creative Commons Attribution License, which permits unrestricted use, distribution, and reproduction in any medium, provided the original work is properly cited.

Hybrid nano-( $\mathrm{SiCp}+\mathrm{TiCp}) / \mathrm{Al}$ composites were fabricated by liquid ultrasonic assisted semisolid stirring processing. The eutectic silicon of $\mathrm{Al}$ matrix changes from acicular to fine granular with addition of nanoparticles and the dendrite size of primary $\alpha$ - $\mathrm{Al}$ decreases with increased nanoparticles. After adding the hybrid nanoparticles with 3 vol\%, the minimum average dendrite size can be refined to $30 \mu \mathrm{m}$. EDS analysis shows that nano-SiCp and -TiCp particles are uniformly dispersed in Al matrix. The YS and UTS of the composites have reached $200 \mathrm{MPa}$ and $228 \mathrm{MPa}$, respectively, which are increased by $34.1 \%$ and $33.3 \%$, respectively. The elongation of the composites has reached $9.8 \%$, which is increased by $40 \%$. The strengthening mechanism of hybrid nano$(\mathrm{SiCp}+\mathrm{TiCp}) / \mathrm{Al}$ composites is mainly Orowan strengthening and minorly Hall-Petch strengthening, and the effect of load transfer strengthening is the least.

\section{Introduction}

Nanoparticles' reinforced aluminum matrix composites have been widely used in automotive and aerospace industry. Strong agglomeration occurs because nanoparticles have a higher wettability than the surface energy and aluminum matrix. At the same time, due to the large surface area of the nanoparticles, the agglomeration of the nanoparticles leads to the decrease of the tensile strength of the composites, especially the decrease of elongation [1-5]. In addition, studies have shown that aluminum matrix and refractory materials (such as carbon materials, $\mathrm{Al} 2 \mathrm{O} 3$, and TiB2) have poor wettability at casting temperature $[1,6-11]$, which is mainly caused by the presence of the oxidation layer in molten aluminum. Therefore, improved wettability of nanoparticles and aluminum matrix is another problem to be solved. To solve this problem, the method of ultrasonic treatment and stirring casting can be used to add nanoparticles directly to aluminum melt to prepare nanocomposites [7, 12-15]. Ultrasonic treatment is considered to be an effective measure to destroy the oxide layer of the aluminum matrix, improve the wettability of the reinforcing body particles and the aluminum matrix, and disperse the nanoparticles $[2,16]$.

Reinforced particles determine the shape, size, and content of the particles according to the performance of the composites and the type of the matrix, so as to optimize the combination between the reinforcement particles and the aluminum matrix $[2,9,17]$ and to make up for some defects of the matrix and improve the comprehensive performance of the composites. $\mathrm{SiC}$ particles have high strength, high hardness, high elastic modulus, excellent performance, and low cost and can greatly improve the tensile strength and hardness of the matrix when used to strengthen aluminum alloy [18]. After adding reinforced particles, the composites show higher use temperature, strength, higher wear resistance, and lower coefficient of thermal expansion of the matrix alloy [19]. In recent decades, nanoparticle-reinforced aluminum matrix composites mainly represented by nano-SiCp/Al composites or nano-TiCp/Al composites have been extensively studied at home and abroad. The research mainly focuses on the preparation method, microstructure, physical properties, mechanical properties, strengthening mechanism, 
deformation, and fracture behavior. Wang et al. [20-23] studied the effect of nano-TiC0.5N0.5 particles on the microstructure of Al-10Si alloy and found that the use of stirring casting and ultrasonic dispersion of nanoparticles can effectively inhibit the growth of eutectic phase and primary phase, so as to effectively refine the microstructure and improve the mechanical properties of the matrix alloy, especially the elongation. During alloy melt solidification, nanoparticles are pushed to the grain boundary to form a layer of nanoparticles around the grain, which effectively hinders the solute atom transport in the primary phase and thus hinders the growth of the primary phase. A corresponding mathematical model is proposed to predict the size of primary phase, which indicates that the formation of nanoparticle shell is more rapid with the increase of the nanoparticle content. Moreover, nanoparticles can be used as nucleation basement of eutectic silicon phase, and the mechanism of nanoparticle-induced nucleation is proposed. The phase orientation of TiCN nanoparticles and silicon phase is very consistent, and the minimum mismatch rate is only $3.168 \%$, thus effectively promoting the nucleation of eutectic silicon phase. Xuan and Nastac [15] prepared $20 \mathrm{~nm}$ Al2O3/A356 composites by ultrasonic assisted liquid stirring method. $\mathrm{Al} 2 \mathrm{O} 3$ nanoparticles are evenly dispersed after ultrasonic assisted treatment because the influence of the cooling rate of nanoparticles during solidification may be included in or repelled from the solid phase. Nanoparticles can refine the microstructure of A356 alloy, which makes the grain become round and reduce the dendritic growth. Because $\mathrm{Al} 2 \mathrm{O} 3$ nanoparticles exist as nucleation points, the eutectic silicon phase has also been partially modified, but the modification mechanism remains to be studied. Choi et al. [24] prepared $1 \mathrm{wt} \% 25 \mathrm{~nm} \mathrm{Al2O} 3 / \mathrm{A} 356$ composites by the ultrasonic assisted liquid stirring method. Al2O3 nanoparticles can be used as the nucleation substrate of $\alpha$ - $\mathrm{Al}$ and eutectic silicon phase. The microstructure of aluminum alloy is refined and the YS is not greatly improved because $\mathrm{Mg}$ reacts with $\mathrm{Al} 2 \mathrm{O} 3$ nanoparticles during heat treatment. Choi et al. $[25,26]$ prepared $50 \mathrm{~nm} \mathrm{Al2O} / \mathrm{Al}-20 \mathrm{Si}-4.5 \mathrm{Cu}$ composites by ultrasonic assisted liquid stirring. After adding $0.5 \mathrm{wt} \%$ nanoparticles, the tensile strength, yield strength, and elongation of the composites are significantly improved, the primary silicon phase is refined. Liu et al. $[10,27,28]$ prepared nano-TiCp/Al composites by the molten fluoride salt method. KAlF4 and nano-TiCp were mixed evenly, added into molten aluminum alloy, and then stirred continuously to destroy $\mathrm{Al} 2 \mathrm{O} 3$ film. Intermediate composites with volume fraction of $9 \%$ were prepared. After secondary remelting and dilution, nanocomposites with volume fraction of $1.8 \%, 3.6 \%, 5.4 \%$, and $7.2 \%$ were prepared, respectively. A large number of nanoparticles are contained into the $\mathrm{Al}$ matrix, and the hardness reaches 100 $\mathrm{HV}$, which is compared with $30 \mathrm{HV}$ of the pure aluminum matrix. Sree Manu et al. [29] prepared $40 \mathrm{~nm}$ Al2O3/A356 composites with different volume fractions by stirring casting and squeeze casting. The composite casting process can better improve the dendritic structure and solidification characteristics. When the volume fraction is $0.5 \%$, the mechanical properties, thermal properties, and wear resistance of the composites reach the best; $0.5 \% \mathrm{Al} 2 \mathrm{O} 3$ / A356 composites is closely combined with the interface of nanoparticles.

A large number of studies have shown aluminum matrix composites with nanoparticles as reinforcements have stronger comprehensive properties than those with micron particles, and the properties will not only enhance the tensile and yield strength of the material but also improve its toughness and plasticity at the same time $[7,8,13,14,30-38]$. Relevant scholars found that both particle size and shape complexity have a positive effect on the dislocation density at the interface between aluminum matrix and nanoparticles [9, 32, 33]. Nanoparticle-reinforced aluminum matrix composites can enhance the strength without affecting its plasticity, but if excessive nanoparticles are added, it will lead to agglomeration and weaken the strengthening effect [39]. The strengthening of aluminum matrix composites through hybrid particles can not only have the advantages of each component at the same time but also enhance the corresponding mechanical properties, which is consistent with the current demand for structural materials. At present, it is very important to carry out the research on nano-SiCp and -TiCp reinforced aluminum matrix composites. There are few studies on hybrid nanoparticle-reinforced aluminum matrix composites, especially the particles' distribution in hybrid nano$(\mathrm{SiCp}+\mathrm{TiCp})$ reinforced aluminum matrix composites $\alpha-\mathrm{Al}$ dendrite refinement and mechanical properties of composites. Therefore, hybrid nano-(SiCp $+\mathrm{TiCp})$ reinforced A356 alloy matrix composites were prepared by the combination of semisolid stirring and ultrasonic vibration. The effects of hybrid nanoparticles on the microstructure and mechanical properties of the composites were studied.

\section{Experimental Procedures}

The chemical composition of the A356 alloy used in this study is shown in Table 1.

The reinforcement selected in this study is nano-SiC and -TiC particles. The micrographs of nano-SiC particles and size distribution is shown in Figures 1(a) and 1(c). The micrographs of nano-TiC particles and size distribution are shown in Figures 1(b) and 1(d). The performance parameters of the two nanoparticles are shown in Table 2.

Nano-SiCp and $-\mathrm{TiCp}$ were vacuum dried $\left(150^{\circ} \mathrm{C}, 2 \mathrm{~h}\right)$. Place the aluminum alloy in a clay graphite crucible and heat it with a crucible resistance furnace. After complete melting at $750^{\circ} \mathrm{C}$, in order to remove gases and oxides, add hexachloroethane to the aluminum melt for degassing for $2 \mathrm{~min}$, and cool it to a semisolid melt $\left(590^{\circ} \mathrm{C}\right)$. The semisolid melt was mechanically stirred, dry nanoparticles were added to the melt during stirring, and the stirring was continued for $5 \mathrm{~min}$. After stirring, continue heating, disperse it with ultrasonic at $710^{\circ} \mathrm{C}$, immerse the tip of the ultrasonic probe into the melt for about $30 \mathrm{~mm}$, and the ultrasonic time is $15 \mathrm{~min}$. The melt is in the protective atmosphere of highpurity argon during the whole process. After the completion of ultrasonic treatment, continue to raise the temperature to $750^{\circ} \mathrm{C}$ for $5 \mathrm{~min}$. The preheating temperature of golf 
TABle 1: The chemical compositions of A356 alloy used in this study (in wt.\%).

\begin{tabular}{lccccc}
\hline \multirow{2}{*}{ Alloy } & \multicolumn{5}{c}{ Chemical composition (wt.\%) } \\
& $\mathrm{Si}$ & $\mathrm{Mg}$ & $\mathrm{Ti}$ & $\mathrm{Fe}$ & $\mathrm{Al}$ \\
\hline A356 & 6.80 & 0.40 & 0.08 & 0.12 & $\mathrm{Bal}$ \\
\hline
\end{tabular}

T-mould is $500^{\circ} \mathrm{C}$ and then pour it into the preheating mould to complete the preparation of composites' melt. Schematic of the processing method is shown in Figure 2. The standard golf T-mould is selected for pouring composite melt, the mould size $(\mathrm{mm})$ is shown in Figure 3, and the mould material is made of hot rolled steel [2].

The optical microscope (OM), scanning electron microscope (SEM), and energy dispersive spectrometer (EDS) were used for microstructures' observation and analysis. Then, Imagine pro-plus software and line intercept method were used to analyze the average dendrite size of $\alpha$-Al. Before the test, the surface of the samples is polished smooth with sandpaper, and then, $0.5 \%$ HF solution is used for corrosion after alcohol cleaning. All cast samples were machined to the specified dimensions in accordance with ASTM E8. The diameter of tensile test was $3 \mathrm{~mm}$ and the gauge length was $15 \mathrm{~mm}$. Tension and the tensile properties of the samples were studied using a testing machine with a crosshead speed of $1 \mathrm{~mm} / \mathrm{min}$ (INSTRON 3382, Canton, OH, USA). All results were based on the average of three samples.

\section{Results and Discussion}

3.1. Microstructural Characteristics. Figure 4 is the SEM of 2 vol\% hybrid nano-(SiCp + TiCp)/Al composite. As can be seen from Figure 2, for the composites with hybrid nanoparticles, the eutectic silicon changes from needle-like to fine granular and the morphology changes to round. Therefore, nanoparticles contribute to the refinement and modification of A356 alloy. Eutectic silicon phase becomes fine and round without sharp needle-like prominent morphology, and nanoparticles are distributed around eutectic silicon phase; a series of nano-SiCp and -TiCp are also distributed in the eutectic silicon phase, which hinders the growth of the eutectic silicon phase $[21,23,26,40]$. Since the size of nano$\mathrm{TiCp}$ is $30 \mathrm{~nm}$, which is smaller than that of nano-SiCp by $40 \mathrm{~nm}$, the distribution of nano-TiCp can be obscurely distinguished in Figure 4. A large number of nano-SiCp and -TiCp are evenly distributed in $\alpha$-Al matrix. However, there are also several areas where nanoparticles agglomerate. It is shown that ultrasonic assisted semisolid stirring process can well disperse nanoparticles, and a small amount of agglomerated nanoparticles will weaken the effect on growth of $\alpha$-Al phase [13]. After adding nano-SiCp and -TiCp, the silicon phase of the matrix treated by ultrasonic dispersion semisolid stirring casting obviously becomes round. There is no sharp corner of the silicon phase, forming a network connection, which is conducive to improving the mechanical properties of composites. Nano-SiCp and -TiCp is distributed at the grain boundary of the eutectic silicon phase, it can be shown that nanoparticles refine and modify the eutectic silicon phase by hindering the growth of the silicon phase.

The van der Waals force between nanoparticles, the thermal energy of nanoparticles, and the energy barrier preventing nanoparticles from sintering in the melt determine the dispersion between nanoparticles. If the energy barrier is low, the nanoparticles are easier to form clusters. If the energy barrier is high and the van der Waals interaction potential is small, the nanoparticles are not easy to agglomerate in the melt.

At $700^{\circ} \mathrm{C}$, the following equation is used to calculate the interaction potential of nano-SiCp and -TiCp and van der Waals in aluminum melt [41]:

$$
\begin{aligned}
\mathscr{W}_{\mathrm{vdw}} & =-\frac{A}{(6 \mathrm{D})} * \frac{\left(\mathrm{R}_{\mathrm{SiC}} * \mathrm{R}_{\mathrm{TiC}}\right)}{\left(\mathrm{R}_{\mathrm{SiC}}+\mathrm{R}_{\mathrm{TiC}}\right)} \\
A & \approx\left(\sqrt{A_{S i C}}-\sqrt{A_{A l}}\right)\left(\sqrt{A_{T i C}}-\sqrt{A_{A l}}\right),
\end{aligned}
$$

where $\mathrm{A}_{\mathrm{SiC}}, \mathrm{A}_{\mathrm{Al}}$, and $\mathrm{A}_{\mathrm{TiC}}$ are the Hamaker constants for nano-SiCp $(248 \mathrm{zJ})$, molten $\mathrm{Al}(266 \mathrm{zJ})$, and nano-TiCp (140 zJ) [42, 43], respectively, and $\mathrm{R}_{\mathrm{SiC}}$ and $\mathrm{R}_{\mathrm{TiC}}$ are $20 \mathrm{~nm}$ and $10 \mathrm{~nm}$, respectively. The above equation is valid only when two nanoparticles interact through the molten $\mathrm{Al}$ for $D$ larger than about two $\mathrm{Al}$ atomic layers (i.e., $0.4 \mathrm{~nm}$ ) [44]. For $D=0.4 \mathrm{~nm}, \mathscr{W}_{\text {vdw }}$ is $-10.51 \mathrm{zJ}$.

The following equation describes the interface energy barrier [45]:

$$
\begin{aligned}
W(D)= & S_{S i C-T i C}\left(\sigma_{S i C}+\sigma_{T i C}-\sigma_{S i C-A l m e l t}-\sigma_{T i C-A l m e l t}\right) \\
& \cdot \frac{\exp \left(-D-D_{0} / a_{0}\right)\left(D-a_{0}\right)}{D_{0}-a_{0}} .
\end{aligned}
$$

for $\mathrm{D}_{0}<D<a_{0}$, where $\sigma_{S i C}, \sigma_{T i C}, \sigma_{S i C-A l m e l t}$, and $\sigma_{T i C-A l m e l t}$ melt are $1.45 \mathrm{~J} / \mathrm{m}^{2}[44], 1.37 \mathrm{~J} / \mathrm{m}^{2}, 0.73 \mathrm{~J} / \mathrm{m}^{2}$, and $0.97 \mathrm{~J} / \mathrm{m}^{2}$, respectively [46].

The effective interaction area of two spheres is calculated by Langbein approximation:

$$
S_{S i C-T i C}=2 \pi \frac{\left(\mathrm{R}_{\mathrm{SiC}} \times \mathrm{R}_{\mathrm{TiC}}\right)}{\left(\mathrm{R}_{\mathrm{SiC}}+\mathrm{R}_{\mathrm{TiC}}\right)} \mathrm{D}_{0} .
$$

The thermal energy at $700^{\circ} \mathrm{C}$ was $13.44 \mathrm{zJ}$, which was higher than $\left(-\mathscr{W}_{\mathrm{vdw}}\right)$. Interfacial energy barrier was calculated as

$$
\mathscr{W}_{\text {inter }}=\mathrm{W}\left(\mathrm{D}_{0}\right)=1.86 \times 10^{4} \mathrm{zJ}=1300 \mathrm{KT} .
$$

For nano-TiCp in $\mathrm{Al}$ melt at $700^{\circ} \mathrm{C}$, when $D$ was $0.4 \mathrm{~nm}$, the van der Waals interaction potential was

$$
\mathscr{W}_{\text {vdw }}=-37.54 z \mathrm{~J} \text {. }
$$

This thermal energy at $700^{\circ} \mathrm{C}$ was $13.44 \mathrm{zJ}$, which was lower than $-\mathscr{W}_{\mathrm{vdw}}$ of $37.54 z$ J. Interfacial energy barrier is $\mathscr{W}_{\text {inter }}=1.32 \times 10^{4} \mathrm{zJ}$.

For nano-SiCp in $\mathrm{Al}$ melt at $700^{\circ} \mathrm{C}$, when $D$ was $0.4 \mathrm{~nm}$, the van der Waals interaction potential was 


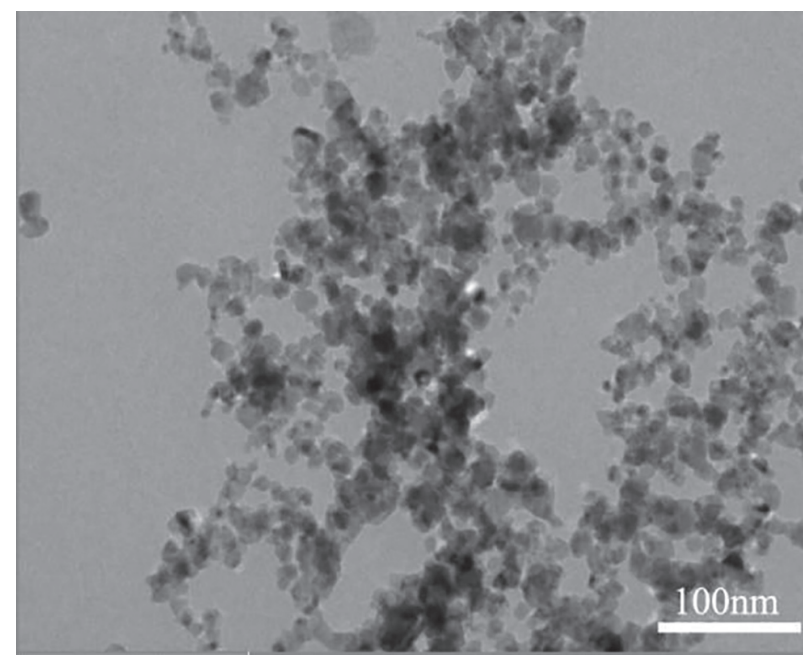

(a)

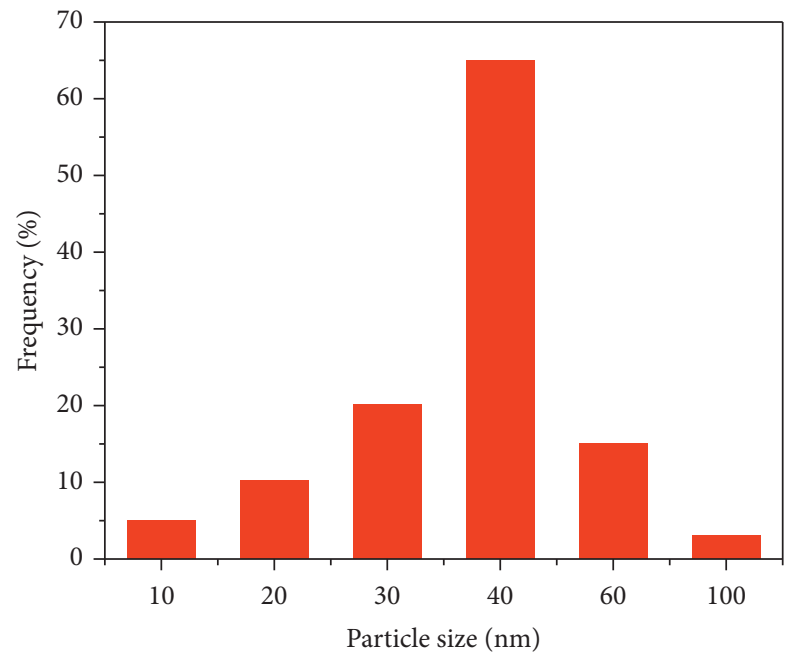

(c)

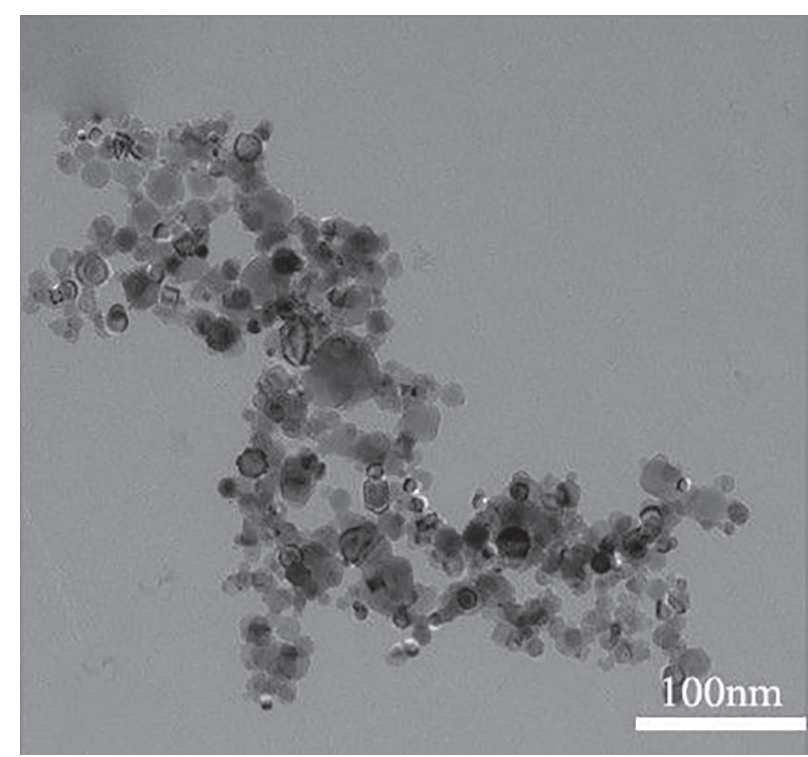

(b)

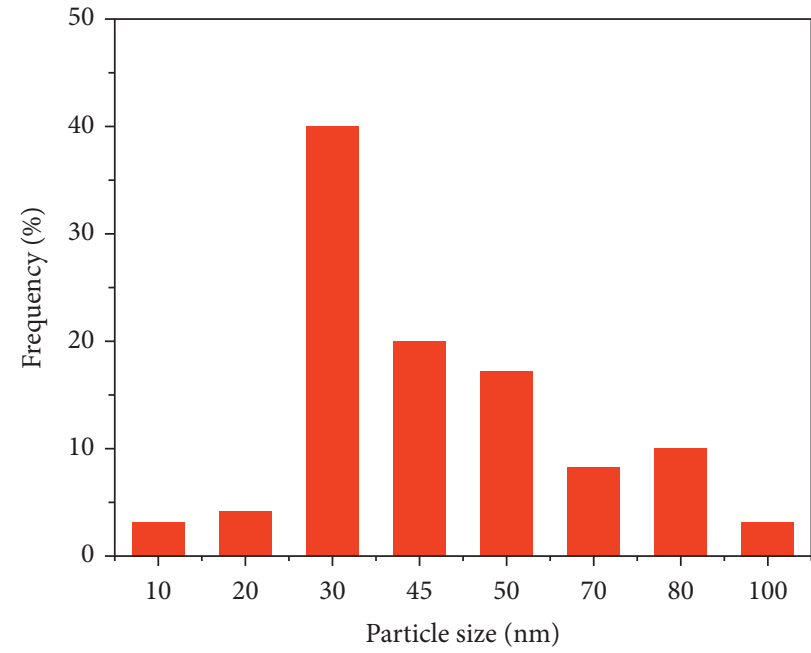

(d)

Figure 1: Reinforcement materials: (a) SiCp; (b) TiCp; (c) SiCp size distribution; (d) TiCp size distribution.

TABLE 2: Performance parameters of reinforcement.

\begin{tabular}{lcccrr}
\hline Nanoparticles & Average particle size $(\mathrm{nm})$ & Purity $(\%)$ & Specific surface area $\left(\mathrm{m}^{2} / \mathrm{g}\right)$ & Bulk density $\left(\mathrm{g} / \mathrm{cm}^{3}\right)$ & Shape \\
\hline SiCp & 40 & 99.9 & 39.8 & 3.21 & Polyhedron \\
TiCp & 30 & 99.9 & 47.3 & 4.93 & Polyhedron \\
\hline
\end{tabular}

$$
\mathscr{W}_{\mathrm{vdw}}=-3.31 z \mathrm{~J}
$$

This thermal energy at $700^{\circ} \mathrm{C}$ was $13.44 \mathrm{zJ}$, which was higher than $-\mathscr{W}_{\mathrm{vdw}}$ of $3.31 \mathrm{zJ}$. Interfacial energy barrier is $\mathscr{W}_{\text {inter }}=3.74 \times 10^{4} \mathrm{zJ}$.

As shown in Table 3, compared with van der Waals interaction potential, interfacial energy barrier, and thermal energy, it can be obtained that nano-TiCp is likely to form clusters, while nano-SiCp tends to be evenly dispersed in aluminum melt. $\mathscr{W}_{\text {inter }}$ of nano-SiCp is much larger than the Brownian potential, so the nano-SiCp cannot achieve adhesive contact. The thermal energy of aluminum melt is much larger than $-\mathscr{W}_{\mathrm{vdw}}$ of nano-TiCp. Therefore, it is easy for nano-SiCp to self-disperse in aluminum melt, resulting in that the clusters composed of nano-SiCp do not exist in the matrix. However, the self-dispersion of nano-TiCp is poor, resulting in the agglomeration of a small amount of nano-TiCp in the matrix [33, 47].

Figure 5 shows the element distribution at the eutectic silicon phase of 2 vol\% nano-(SiCp $+\mathrm{TiCp}) / \mathrm{Al}$ composites. $\mathrm{Si}$ and Ti elements are evenly distributed in $\alpha$ - $\mathrm{Al}$ matrix. It is evenly distributed in grains and grain boundaries. There are 


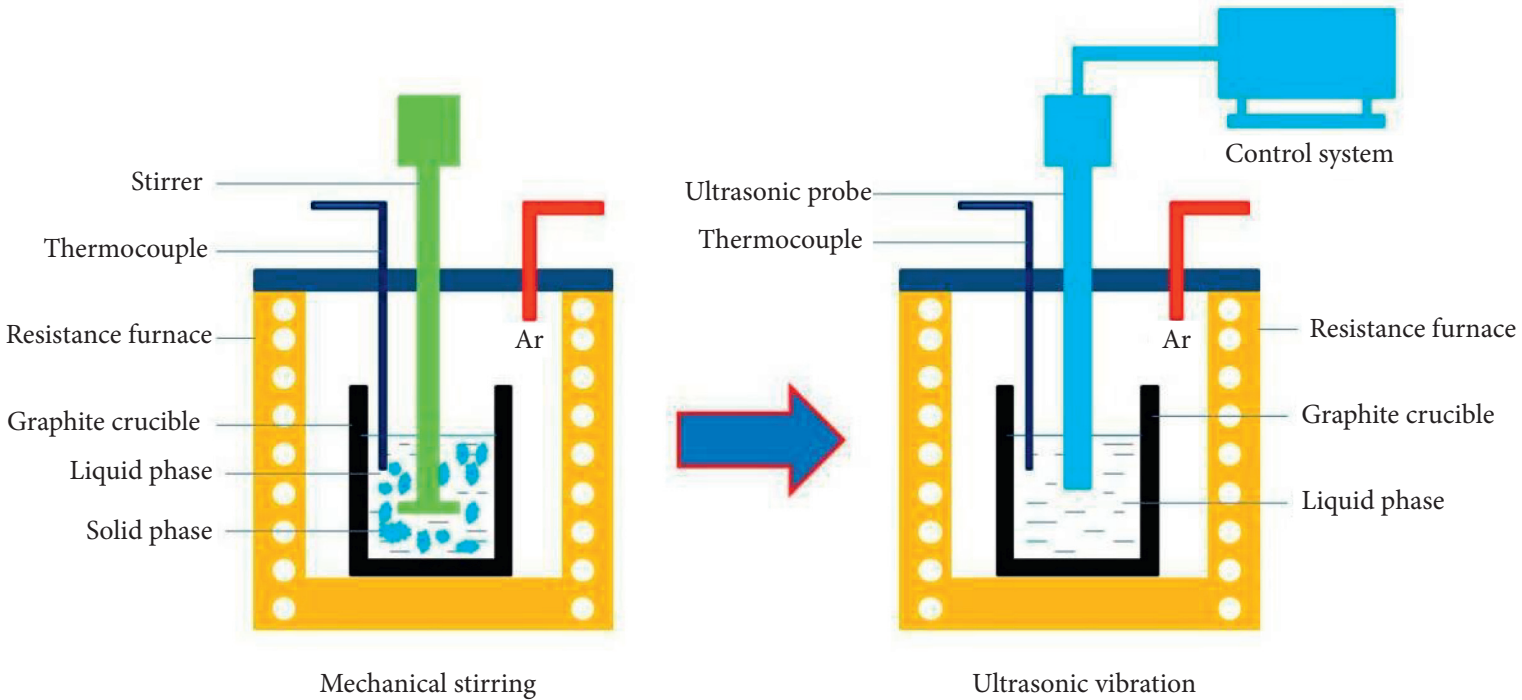

FIgURE 2: Schematic of the processing method for the nanocomposites.

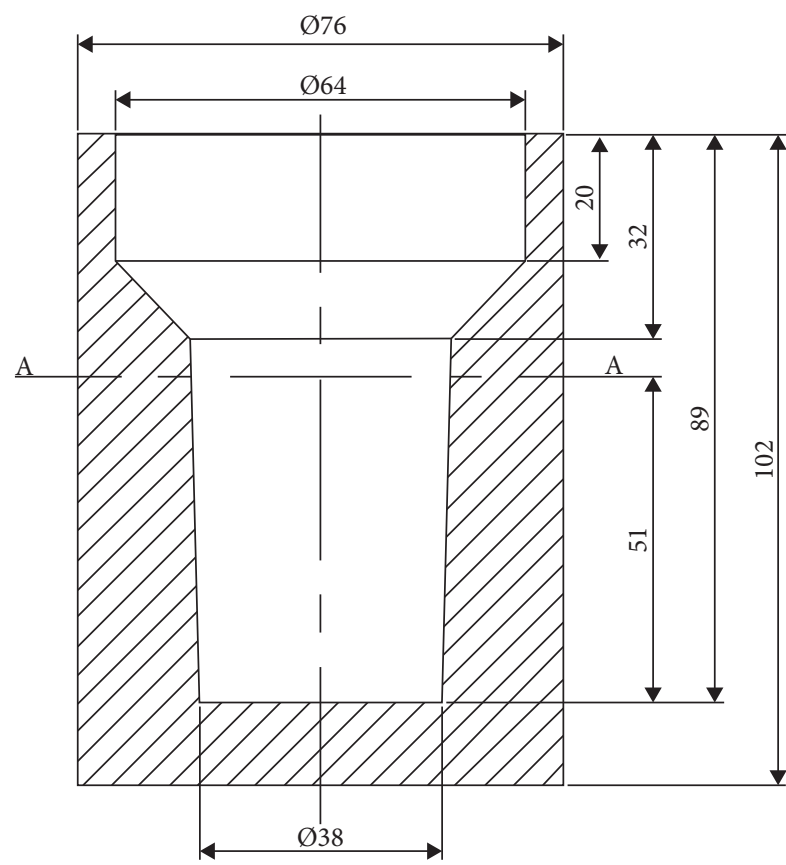

FIgURE 3: Reynolds standard golf T-mould [2].

a large number of $\mathrm{Si}$ and Ti elements in the eutectic silicon phase because the matrix alloy contains Si elements. This also proves the EDS containing Si element. As for the existence of Ti element at the eutectic silicon phase, nano-TiCp is distributed at the around eutectic silicon phase after solidification, resulting in a large number of Ti element in the EDS. It further shows that the uniform dispersion of nanoparticles in the matrix alloy is attributed to ultrasonic assisted dispersion treatment. On the one hand, ultrasonic assisted treatment can produce intermittent bubbles into the agglomerated nanoparticles. When the bubbles grow to a certain volume, the bubbles will break, so as to disperse the agglomerated nanoparticles [7, 16, 48, 49]. On the other hand, the nanoparticles will also contain some other impurity particles, such as $\mathrm{SiO}_{2}$ and $\mathrm{TiO}_{2}$. Hybrid nanoparticles containing impurity particles are also pushed to the front of the solid-liquid interface, resulting in nanoparticles at the grain boundary. Because the wettability of hybrid nanoparticles containing impurity particles and aluminum melt is improved, the impurity particles act as the substrate for heterogeneous nucleation, which improves the heterogeneous nucleation rate of the matrix alloy $[12,13,50,51]$.

\subsection{Effect of Nano-SiCp and-TiCp Content on $\alpha$-Al Dendrite} Size. Figure 6 shows optical microstructures of composites and the matrix alloy. The same content of $2 \mathrm{vol} \%$ hybrid nano- $(\mathrm{SiCp}+\mathrm{TiCp})$ was added $\alpha-\mathrm{Al}$ matrix. The refinement of $\alpha$ - $\mathrm{Al}$ dendrite and secondary dendrite arm is more significant than that of single nanoparticles reinforced. It can be seen from the microstructures that it is spherical $\alpha$ - $\mathrm{Al}$, and the amount of $\alpha$ - $\mathrm{Al}$ dendrites is obviously more. The grain size decreased significantly, with a large decrease and obvious refinement effect. Therefore, the enhancement effect of hybrid nanoparticles is more significant than that of single reinforcement $[12,13]$. From the comparison of Figures 6(d)-6(f), it can be seen that when the content of nanoparticles is $3 \mathrm{vol} \%$ hybrid nano-(SiCp $+\mathrm{TiCp})$, the $\alpha-\mathrm{Al}$ dendrites are further refined and spheroidized $\alpha$-Al phase increased, but the refining effect was not more obvious. Because of the low crystal growth rate, it provided a large degree of undercooling and promoted heterogeneous nucleation $[20-22,52,53]$. A large increase in grain amount leads to a significant grain refinement of nanocomposites. After adding different nanoparticles in the nanocomposites, the grain size of the matrix also changed greatly. The results show that nano-SiCp and -TiCp have strong combined effect on grain refinement. Refinement of $\alpha-\mathrm{Al}$ dendrite and eutectic silicon phase can be explained by the theory of "Smith Zener" pinning effect. Nanoparticles are dispersed at the grain boundary and pushed to the grain boundary at the 


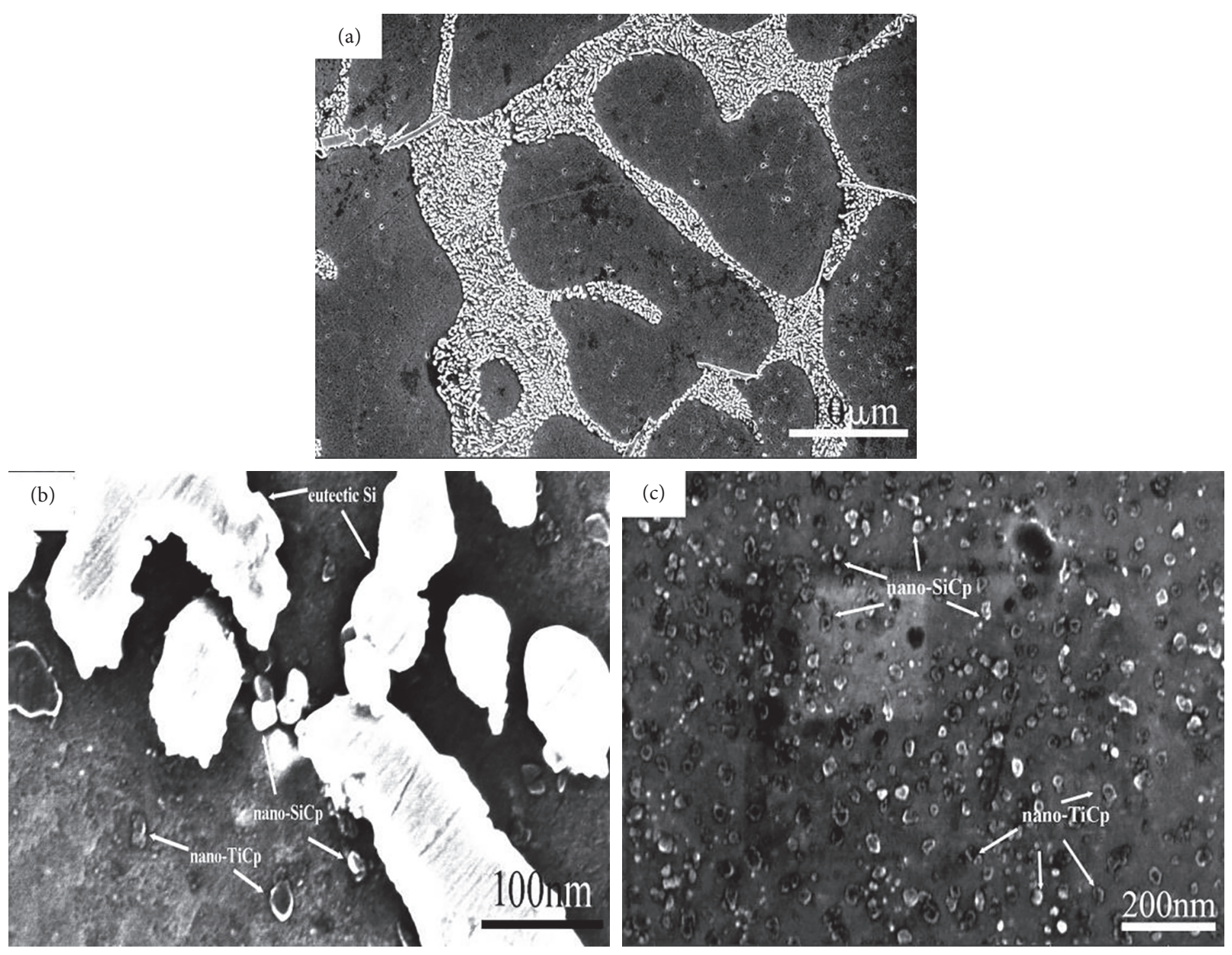

Figure 4: Scanning electron microscope (SEM) of 2 vol\% hybrid nano-(SiCp + TiCp)/Al composites. (a) Low magnification; (b) eutectic silicon and $\alpha$-Al phase; (c) $\alpha$-Al phase.

front of the liquid-solid interface, which hinders the growth of grain boundary and refine $\alpha$-Al dendrite and eutectic silicon phase $[22,23,26,54]$.

The dendrite size variation with the addition of nanoSiCp and -TiCp is plotted in Figure 7. When the content of nanoparticles is $2 \mathrm{vol} \%$, the dendrite size of $\alpha-\mathrm{Al}$ is $50 \mu \mathrm{m}$ with hybrid nanoparticles reinforced. The dendrite size of $\alpha$-Al is $68 \mu \mathrm{m}$ (nano $\mathrm{SiCp}$ ) and $70 \mu \mathrm{m}$ (nano TiCp) with single nanoparticles reinforced. When the content of nanoparticles is 3 vol\% hybrid nano-( $\mathrm{SiCp}+\mathrm{TiCp})$, the $\alpha$ - $\mathrm{Al}$ dendrites are further refined and the spheroidized $\alpha$-Al phase increased and the minimum dendrite size can be refined to $30 \mu \mathrm{m}$. The dendrite size of $\alpha-\mathrm{Al}$ is $50 \mu \mathrm{m}$ (nano $\mathrm{SiCp}$ ) and $53 \mu \mathrm{m}$ (nano TiCp) with single nanoparticles reinforced because with the further increase of the content of nanoparticles, the distribution of nanoparticles in the aluminum matrix appears particle agglomeration. In the lowand high-content areas of nanoparticles in the composite, the influence of nanoparticles in the former area on the development of dendrites is small and the effect of refinement is poor. The growth range of $\mathrm{Al}$ dendrite increases, so a very small $\alpha$-Al spheroidized phase appears. In the latter region, nanoparticles have a great influence on the development of dendrites and a good effect of refinement. The reason why the enhancement effect of hybrid nanoparticles is more obvious is that the wettability of nano-TiCp and aluminum melt is better than that of nano-SiCp and aluminum melt $[33,54,55]$. In addition, because nano-TiCp has greater lattice matching with aluminum matrix, nano-TiCp is easier to act as heterogeneous nucleation than nano-SiCp with $\alpha$-Al dendrite nucleation substrate [33, 54, 55]. A large number of hybrid nano-(SiCp $+\mathrm{TiCp})$ can become $\alpha-\mathrm{Al}$ effective heterogeneous nucleation core. Therefore, as the content of hybrid nanoparticles increases, the dendrite size of $\alpha$-Al becomes smaller and can be hindered by the hybrid nano- $(\mathrm{SiCp}+\mathrm{TiCp})$ pushed by the front of the solidification interface $\alpha$-Al dendrite growth, thus refinement $\alpha$-Al dendrite $[12,13,31]$, in which hybrid nano-( $\mathrm{SiCp}+\mathrm{TiCp})$ hindering dendrite growth is the main reason.

3.3. Tensile Properties. Figure 8 gives the engineering stressstrain curves and tensile properties of hybrid nano$(\mathrm{SiCp}+\mathrm{TiCp}) / \mathrm{Al}$ composites with different volume fractions. As can be seen, the proportion of nanoparticles added to hybrid nano-( $\mathrm{SiCp}+\mathrm{TiCp}) / \mathrm{Al}$ composites gradually increased; ultimate tensile strength (UTS), yield strength (YS), and elongation of hybrid nano- $(\mathrm{SiCp}+\mathrm{TiCp}) / \mathrm{Al}$ composites 
TABLE 3: Thermal energy and interfacial energy barrier of composites.

\begin{tabular}{lccc}
\hline Materials & Van der Waals interaction potential $\left(-\mathscr{W}_{\text {vdw }}\right)$ & Interfacial energy barrier & Thermal energy \\
\hline Al & -- & $1.86 \times 10^{4} \mathrm{zJ}$ & $13.44 \mathrm{zJ}$ \\
SiCnp & $3.31 \mathrm{zJ}$ & $3.74 \times 10^{4} \mathrm{zJ}$ & -- \\
TiCnp & $37.54 \mathrm{zJ}$ & $1.32 \times 10^{4} \mathrm{zJ}$ & -- \\
\hline
\end{tabular}
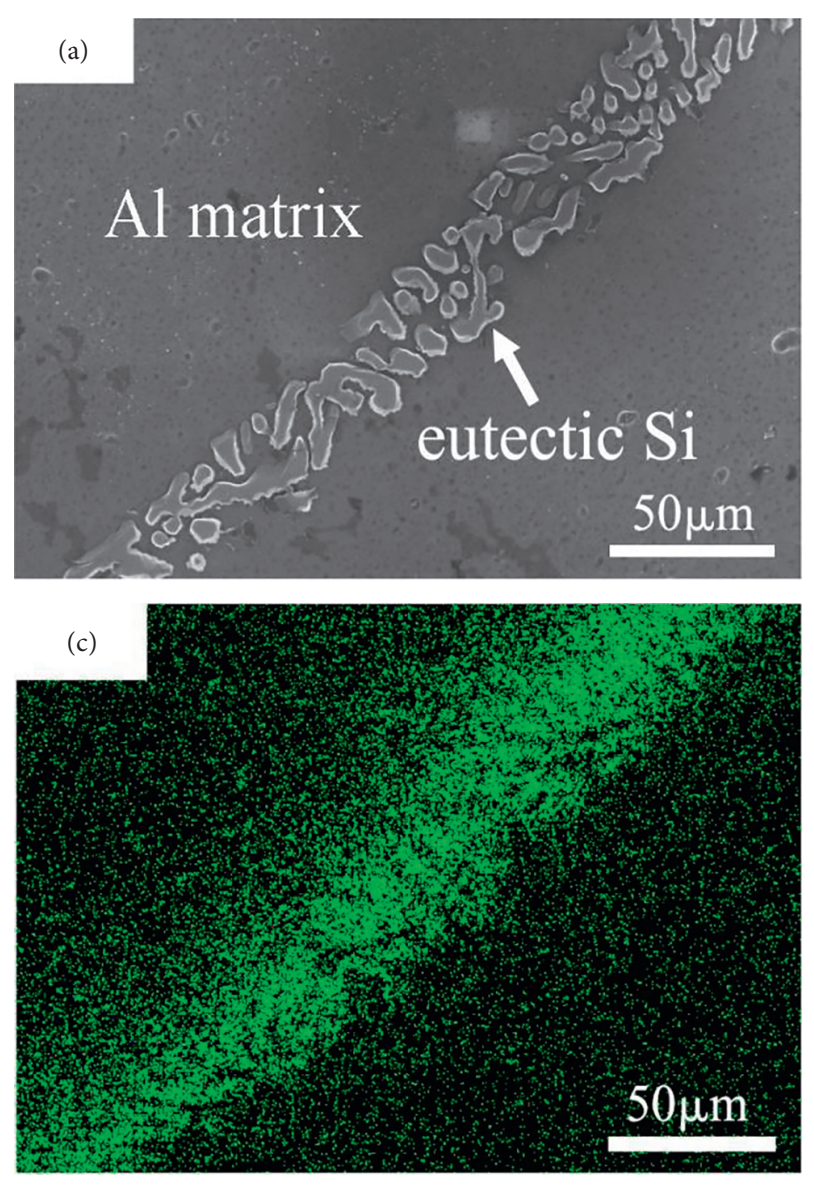

FIGURE 5: EDS of eutectic structure and $\alpha$-Al phase of 2 vol\% hybrid nano-(SiCp + TiCp)/Al composites: (a) SEM image; (b) distribution of nano-SiCp and -TiCp; EDS of (c) Si K and (d) Ti K.

were significantly improved than those of single nanoparticle reinforced A356 composites. As can be seen from Figure $8(\mathrm{~b})$, after adding 1 vol\% nanoparticles, YS and UTS of the composites reached $175 \mathrm{MPa}$ and $198 \mathrm{MPa}$, respectively. Compared with the matrix alloy, YS and UTS of the composites were increased by $16.6 \%$ and $16.5 \%$, and elongation increased by $7 \%$. After adding 2 vol\% nanoparticles, YS and UTS of the composites reached $187 \mathrm{MPa}$ and $210 \mathrm{MPa}$, respectively. The elongation of the composites is $8.5 \%$, which is increased by $21.4 \%$.

After adding the nanoparticles with the 3 vol\%, YS and UTS of the composites reach $200 \mathrm{MPa}$ and $228 \mathrm{MPa}$, respectively, YS and UTS of the composite increased by $33.3 \%$ and $34.1 \%$, and elongation of the composites is $9.8 \%$, which is increased by $40 \%$. When the content of nanoparticles were 3 vol\%, the UTS and YS were greatly improved and elongation was significantly improved. (b)

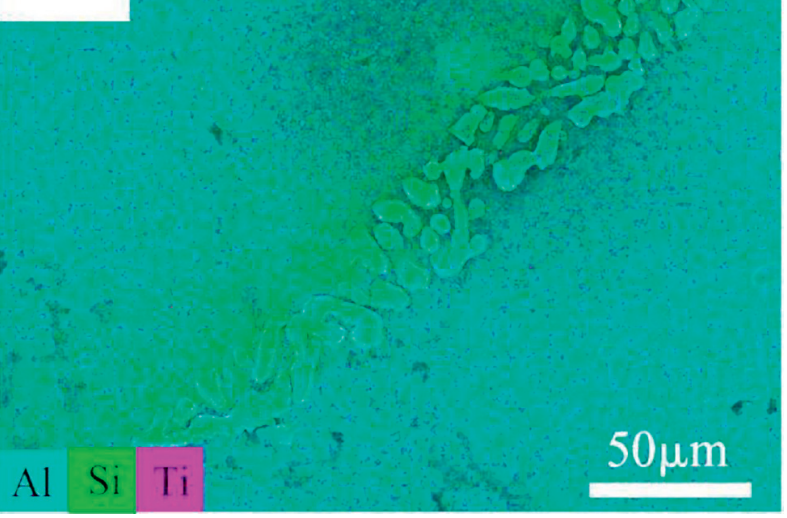

(d)

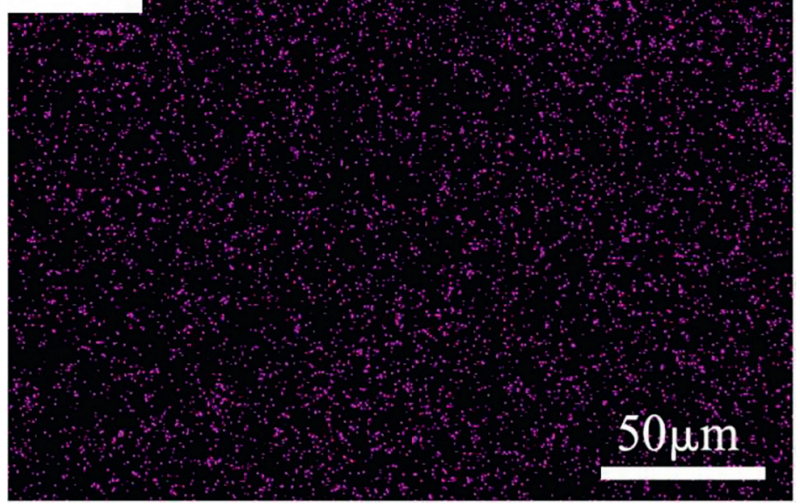

Nano-SiCp and -TiCp exist in around the eutectic silicon phase and uniformly distributed in the aluminum matrix. Therefore, the distance distribution between particles is relatively uniform; the effect of restraining and limiting dislocation slip in aluminum alloy matrix becomes stronger. The continuous damage of nano-SiCp and -TiCp to the matrix is reduced, and the plastic strength of the composite is increased. Therefore, considering that the nanoparticles are smaller and the addition of nanoparticles with the same volume fraction has a stronger optimization effect on the properties of composites, the distance between particles is further reduced, the Orowan strengthening effect is enhanced, and the strength is significantly improved $[7,9,13,14,39,56]$.

Improved strength of metal matrix nanocomposites mainly depends on three strengthening mechanisms: Orowan strengthening mechanism, load transfer mechanism, and 

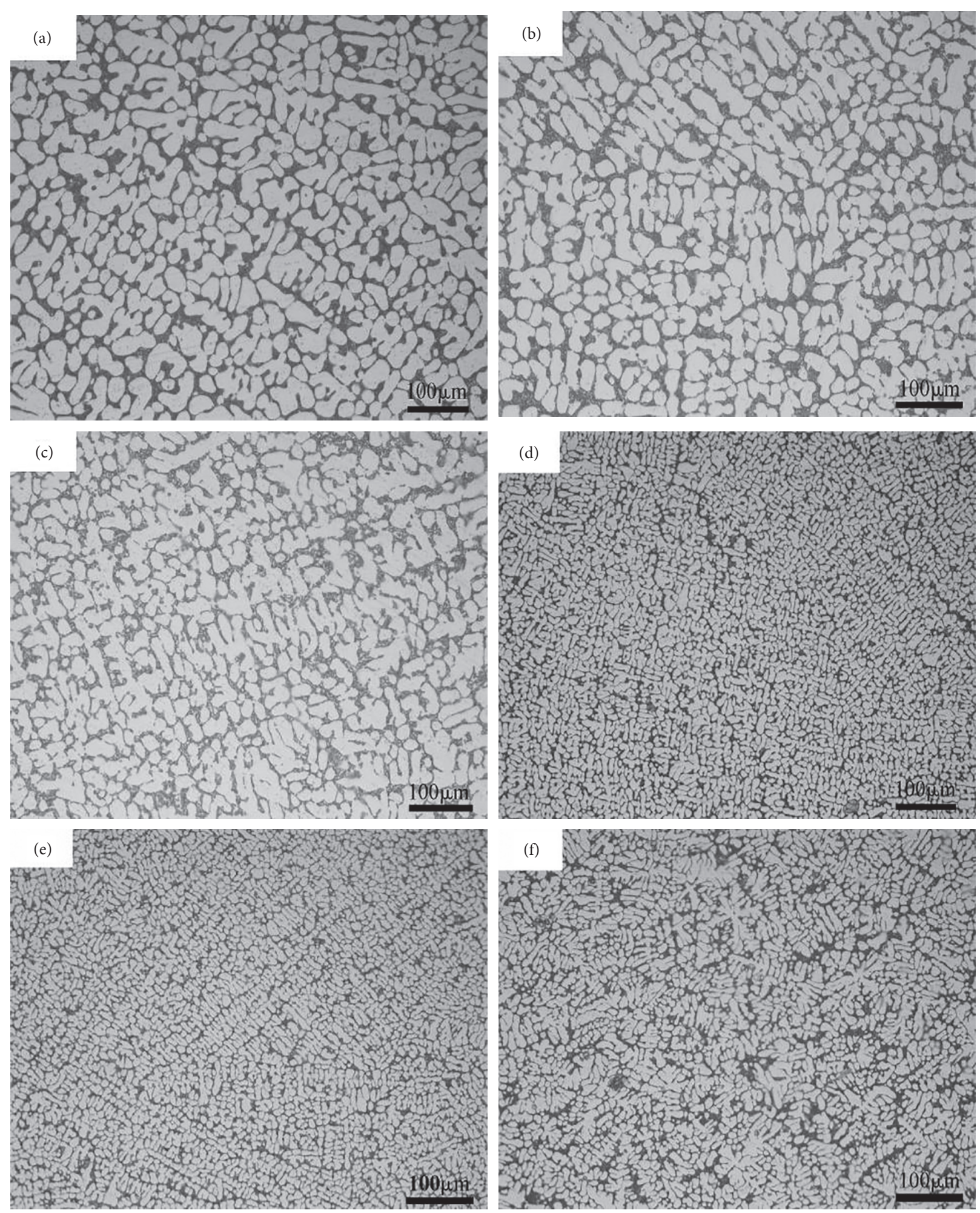

Figure 6: Optical microstructures of hybrid nano-( $\mathrm{SiCp}+\mathrm{TiCp}) / \mathrm{Al}$ composites: (a) 2 vol\% hybrid nano-( $\mathrm{SiCp}+\mathrm{TiCp}) / \mathrm{Al}$; (b) 2 vol\% nano$\mathrm{SiCp} / \mathrm{Al}$; (c) 2 vol\% nano-TiCp/Al; (d) 3 vol\% hybrid nano-(SiCp + TiCp)/Al; (e) 3 vol\% nano-SiCp/Al; (f) 3 vol\% nano-TiCp/Al.

Hall-Petch strengthening mechanism [56]. Smaller nanoparticles lack the ability to produce sufficient strain, and the strengthening caused by the increasing of dislocation can be ignored [13]. Therefore, only three strengthening mechanisms play a role in improving YS in aluminum matrix nanocomposites, mainly relying on three strengthening mechanisms. The following equation contributes to the calculation of the Hall-Petch strengthening mechanisms [56]: 


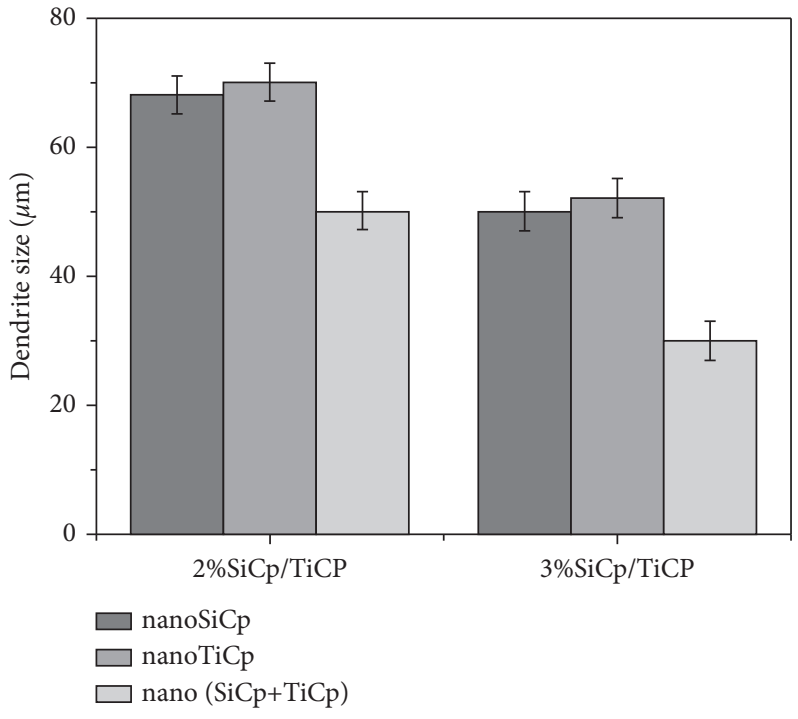

Figure 7: The dendrite size of $\alpha$-Al in hybrid nano-( $\mathrm{SiCp}+\mathrm{TiCp}) / \mathrm{Al}$ composites.

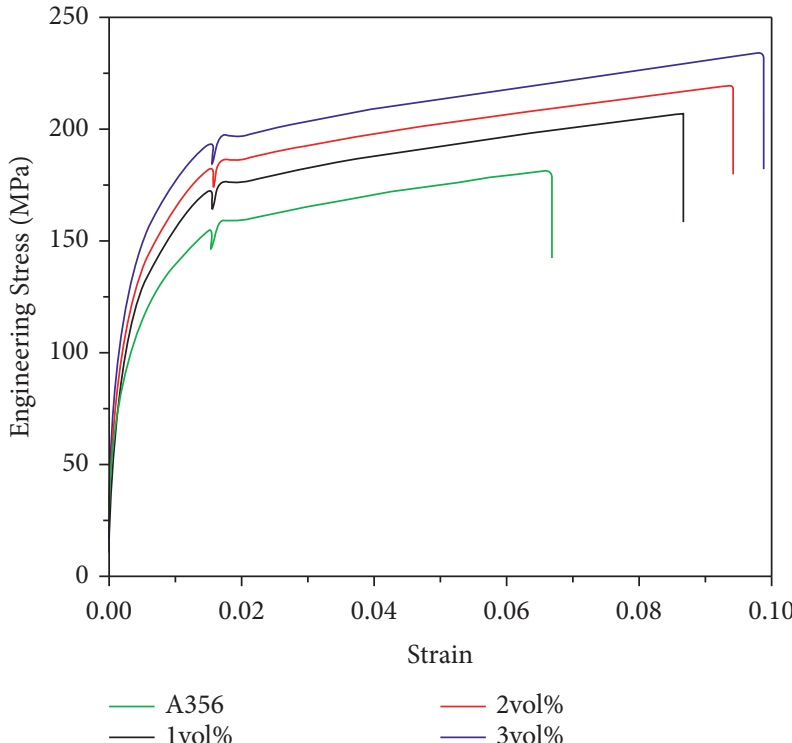

(a)

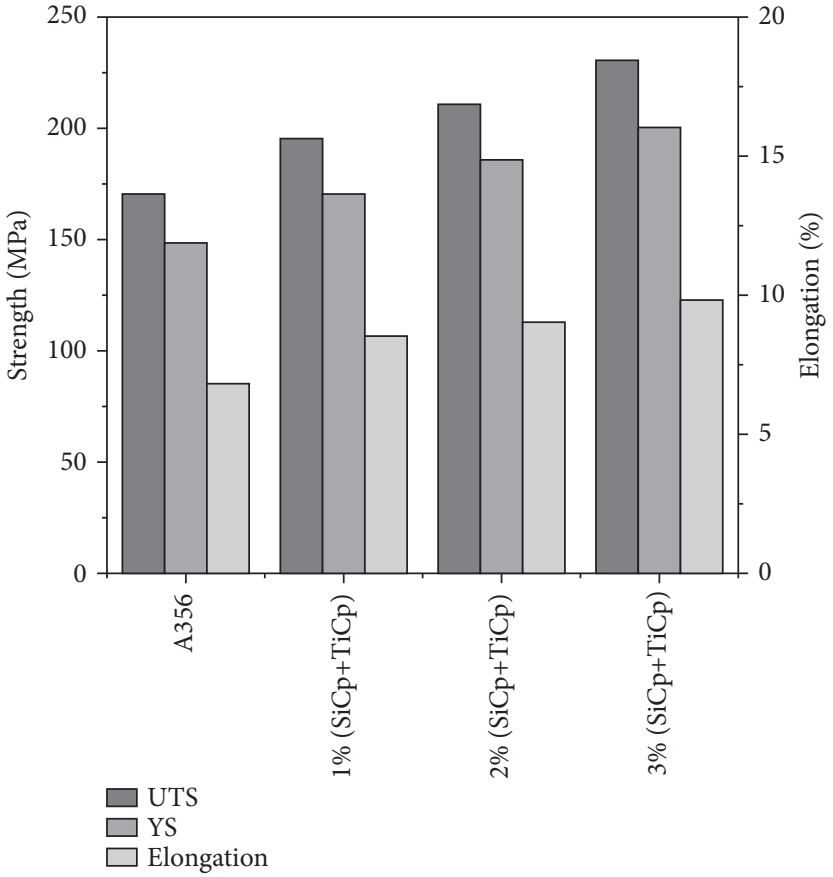

(b)

FIGURE 8: Engineering strain-stress curves and tensile properties of hybrid nano-( $\mathrm{SiCp}+\mathrm{TiCp}) / \mathrm{Al}$ composites: (a) engineering strain-stress curves; (b) UTS, YS, and elongation.

$$
\sigma_{H-P}=K_{y}\left(D^{-1 / 2}-D_{0}^{-1 / 2}\right)
$$

where $D$ and $D_{0}$ are the grain sizes of nanocomposites and the matrix alloy, respectively, and $K_{y}$ is a constant. The Hall-Petch relationship in aluminum alloys was studied by Loucif et al. [57]. $K_{y}$ value of aluminum alloy at the room temperature is $0.326 \mathrm{MPam}^{1 / 2}$ [57]. Due to the grain refinement in hybrid nano- $(\mathrm{SiCp}+\mathrm{TiCp}) / \mathrm{Al}$, added nanoparticles are $3 \mathrm{vol} \%$ that the calculated $\sigma_{H-P}$ in the YS of hybrid nano-( $\mathrm{SiCp}+\mathrm{TiCp}) / \mathrm{Al}$ was $23 \mathrm{MPa}$.

The following equation is used to calculate the YS increment generated by the Orowan strengthening mechanism induced by dispersed nanoparticles [58]:

$$
\sigma_{O}=\frac{0.13 G_{m} b}{\lambda} \ln \frac{d_{p}}{2 b}
$$




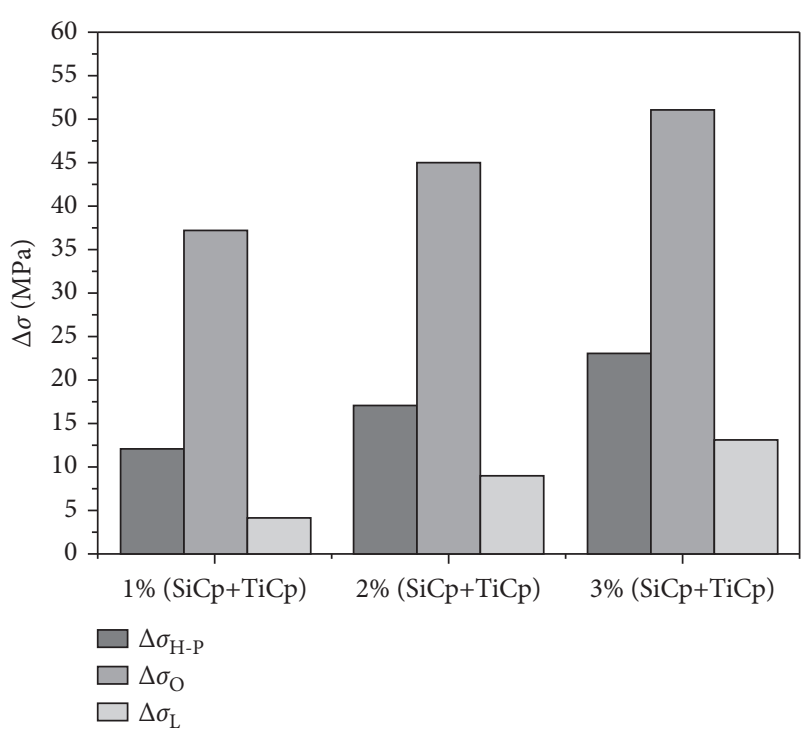

Figure 9: The contribution of different strengthening mechanisms to the YS of composites.

where $b, d_{p}, \lambda$, and $G_{m} m$ are the size of the nanoparticles, the interparticle spacing, the Burgers vector, and the shear modulus of the matrix, respectively. $\lambda$ is the spacing of nanoparticles and can be described by the following equation:

$$
\lambda \approx d_{p}\left[\left(\frac{1}{2 v_{p}}\right)^{1 / 3}-1\right],
$$

where $d_{p}$ and $v_{p}$ are the particles' size and volume fraction of the reinforcement, respectively.

In this study, calculate the value for $\sigma_{O}=51 \mathrm{MPa}$ for $G_{m}=2.54 \times 10^{4} \mathrm{~Pa}$ and $b=0.3 \mathrm{~nm}$.

Nanoparticles are added into the aluminum alloy matrix. When the load is applied to the composite, the nanoparticles and the matrix bear the load together, and the load is transmitted from the matrix to the nanoparticles through the interface. The good interface between the dispersed nanoparticles and the matrix is helpful to transfer the load from the matrix to the nanoparticles. Therefore, the load transfer mechanism is considered. Calculate the strength increase generated by the load transfer mechanism, which is calculated by the following equation [59]:

$$
\sigma_{L}=0.5 f \sigma_{m}
$$

where $\sigma_{m}$ is the YS of matrix and $f$ is the volume fraction of nanoparticles. The calculated $\sigma_{L}$ load was $13 \mathrm{MPa}$.

Hall-Petch strengthening mechanism, Orowan strengthening mechanism, and load transfer mechanism should be considered to estimate the YS of hybrid nano-(SiCp + TiCp)/ Al. The improved Clyne model was proposed by Sanaty Zadeh, which is more accurate than other methods [60]:

$$
\begin{aligned}
\sigma & =\sqrt{\left(\sigma_{L}\right)^{2}+\left(\sigma_{H-P}\right)^{2}+\left(\sigma_{O}\right)^{2}}, \\
\sigma_{\mathrm{YC}} & =\sigma_{\mathrm{YM}}+\sigma,
\end{aligned}
$$

where $\sigma_{\mathrm{YC}}$ is the YS of the composites and $\sigma_{\mathrm{YM}}$ is the YS of the matrix.

The theoretical $\sigma_{\mathrm{YC}}$ of hybrid nano-( $\left.\mathrm{SiCp}+\mathrm{TiCp}\right) / \mathrm{Al}$ is close to the experimental value, which is $203 \mathrm{MPa}$ and $200 \mathrm{MPa}$. Hindering the movement of dislocations is caused by the Orowan strength mechanism produced by uniformly distributed nanoparticles. In terms of tensile properties, three strength mechanisms of hybrid nanocomposites were activated, which confirmed the uniformly distribution of nanoparticles. The contribution of different strengthening mechanisms to the YS of composites is shown in Figure 9. Hybrid nanoparticles are randomly and uniformly distributed in the matrix, and the pinning effect of nanoparticles on the motion of dislocation is stronger than that of single nanoparticles reinforced [57, 59-62]. Because the hardness of nano-SiCp and -TiCp is different, the force of dislocation bypassing nanoparticles is different, the force of dislocation bypassing is enhanced, and the strength of the composites is gradually enhanced. The effect of hybrid nanoparticles on grain refinement is also better than that of single nanoparticles reinforced. According to the Hall-Petch strengthening mechanism, the finer the grain, the higher the strength of the composites [12-14, 56].

As shown in Figure 9, the main strengthening mechanism to improve the mechanical properties of composites is Orowan strengthening mechanism, and the strengthening effect produced by Hall-Petch strengthening mechanism is secondary. The load transfer mechanism has the least effect on the mechanical properties of composites. Compared with nano-SiCp/Al and nano-TiCp/Al, hybrid nano$(\mathrm{SiCp}+\mathrm{TiCp}) / \mathrm{Al}$ with $\alpha$ - $\mathrm{Al}$ dendrite size is the smallest. In addition, elongation is an index to describe the plasticity of composites; the hybrid nanomaterial ( $\mathrm{SiCp}+\mathrm{TiCp}) / \mathrm{Al}$ has the largest elongation. The results show that the hybrid nano-(SiCp $+\mathrm{TiCp}) / \mathrm{Al}$ has good plasticity and ductility. Finer grain hinders the movement of dislocation in alloy. Therefore, the generation of cracks can be avoided and the plasticity can be improved [7, 33].

\section{Conclusions}

(1) The composites prepared by the ultrasonic-assisted semisolid stirring method can disperse the nanoparticles evenly; the nanoparticles are helpful to the refinement and modification of $\alpha$-Al dendrite and eutectic silicon phase. For the composites with nanoparticles, the eutectic silicon changes from needle to fine particles, and the morphology changes to coral. A small amount of agglomeration appears in the $\mathrm{Al}$ matrix with nano-SiCp and -TiCp. When 3 vol $\%$ of hybrid nano-(SiCp $+\mathrm{TiCp})$ is added, the minimum dendrite size of $\alpha-\mathrm{Al}$ can be refined to $30 \mu \mathrm{m}$.

(2) With the increase of nanoparticles' content, the YS, UTS, and elongation of the composites will increase gradually. After adding the nanoparticles with 3 vol $\%$, the YS and UTS of composites reached $200 \mathrm{MPa}$ and $228 \mathrm{MPa}$, respectively, the UTS and YS of composites are increased by $34.1 \%$ and $33.3 \%$, and 
the elongation of composites is $9.8 \%$, which is increased by $40 \%$.

(3) For nanoparticles' reinforced A356 matrix composites, Orowan strengthening mechanism is the main strengthening mechanism improving the mechanical properties of the composites; the strengthening effect produced by Hall-Petch strengthening mechanism is secondary. The load transfer mechanism has the least effect on the mechanical properties of the composites.

\section{Data Availability}

All data generated or analyzed during this study are included within the article.

\section{Conflicts of Interest}

The authors declare that there are no conflicts of interest regarding the publication of this paper.

\section{Acknowledgments}

This research has been supported by the Aviation Foundation of China.

\section{References}

[1] A. Javadi, C. Cao, and X. Li, "Manufacturing of Al-TiB 2 nanocomposites by flux-assisted liquid state processing," Procedia Manufacturing, vol. 10, pp. 531-535, 2017.

[2] Y. Yang, J. Lan, and X. Li, "Study on bulk aluminum matrix nano-composite fabricated by ultrasonic dispersion of nanosized SiC particles in molten aluminum alloy," Materials Science and Engineering, vol. 380, no. 1, pp. 378-383, 2004.

[3] L.-Y. Chen, H. Konishi, A. Fehrenbacher et al., "Novel nanoprocessing route for bulk graphene nanoplatelets reinforced metal matrix nanocomposites," Scripta Materialia, vol. 67, no. 1, pp. 29-32, 2012.

[4] L.-Y. Chen, D. Weiss, J. Morrow, J.-Q. Xu, and X.-C. Li, “A novel manufacturing route for production of high-performance metal matrix nanocomposites," Manufacturing Letters, vol. 1, no. 2, pp. 62-65, 2013.

[5] L.-Y. Chen, J.-Y. Peng, J.-Q. Xu, H. Choi, and X.-C. Li, "Achieving uniform distribution and dispersion of a high percentage of nanoparticles in metal matrix nanocomposites by solidification processing," Scripta Materialia, vol. 69, no. 8 , pp. 634-637, 2013.

[6] X.-H. Chen and H. Yan, "Solid-liquid interface dynamics during solidification of $\mathrm{Al}$ 7075-Al2O3np based metal matrix composites," Materials \& Design, vol. 94, pp. 148-158, 2016.

[7] D. Yuan, K. Hu, S. Lü, S. Wu, and Q. Gao, "Preparation and properties of nano-SiCp/A356 composites synthesised with a new process," Materials Science and Technology, vol. 34, no. 12, pp. 1415-1424, 2018.

[8] M. Mollaei, M. Azadi, and H. Tavakoli, "A parametric study on mechanical properties of aluminum-silicon/SiO2 nanocomposites by a solid-liquid phase processing," Applied Physics A, vol. 124, no. 7, p. 504, 2018.

[9] A. Javadi, S. Pan, and X. Li, "Fabrication of high strength Al nanocomposites with populous TiB2 nanoparticles," Procedia Manufacturing, vol. 26, pp. 629-632, 2018.
[10] C. Cao, W. Liu, A. Javadi, H. Ling, and X. Li, "Scalable manufacturing of $10 \mathrm{~nm}$ TiC nanoparticles through molten salt reaction," Procedia Manufacturing, vol. 10, pp. 634-640, 2017.

[11] I. El-Mahallawi, H. Abdelkader, L. Yousef, A. Amer, J. Mayer, and A. Schwedt, "Influence of $\mathrm{Al} 2 \mathrm{O} 3$ nano-dispersions on microstructure features and mechanical properties of cast and T6 heat-treated Al Si hypoeutectic Alloys," Materials Science and Engineering, vol. 556, pp. 76-87, 2012.

[12] Y. C. Guo, K. B. Nie, X. K. Kang, K. K. Deng, J. G. Han, and Z. H. Zhu, "Achieving high-strength magnesium matrix nanocomposite through synergistical effect of external hybrid ( $\mathrm{SiC}+\mathrm{TiC})$ nanoparticles and dynamic precipitated phase," Journal of Alloys and Compounds, vol. 771, pp. 847-856, 2019.

[13] D. Jiang and J. Yu, "Fabrication of Al2O3/SiC/Al hybrid nanocomposites through solidification process for improved mechanical properties," Metals, vol. 8, no. 8, p. 572, 2018.

[14] D. P. Jiang and J. K. Yu, "Mg improves the distribution of Al 2 O 3 nanoparticles in an Al matrix via solidification," Materials Research Express, vol. 6, no. 2, p. 026554, 2019.

[15] Y. Xuan and L. Nastac, "The role of ultrasonic cavitation in refining the microstructure of aluminum based nanocomposites during the solidification process," Ultrasonics, vol. 83, pp. 94-102, 2018.

[16] K. S. Suslick, Y. Didenko, M. M. Fang et al., "Acoustic cavitation and its chemical consequences," Philosophical Transactions of the Royal Society A: Mathematical, Physical \& Engineering Sciences, vol. 357, no. 1751, 1999.

[17] A. R. Kennedy, A. E. Karantzalis, and S. M. Wyatt, "The microstructure and mechanical properties of $\mathrm{TiC}$ and $\mathrm{TiB} 2$ reinforced cast metal matrix composites," Journal of Materials Science, vol. 34, no. 5, pp. 933-940, 1999.

[18] S. Lü, P. Xiao, D. Yuan, K. Hu, and S. Wu, "Preparation of Al matrix nanocomposites by diluting the composite granules containing nano-SiCp under ultrasonic vibaration," Journal of Materials Science \& Technology, vol. 34, no. 9, pp. 1609-1617, 2018.

[19] K. Amouri, S. Kazemi, A. Momeni, and M. Kazazi, "Microstructure and mechanical properties of Al-nano/micro $\mathrm{SiC}$ composites produced by stir casting technique," Materials Science and Engineering, vol. 674, pp. 569-578, 2016.

[20] K. Wang, H. Y. Jiang, Q. D. Wang, and W. J. Ding, "Influence of nanoparticles on microstructural evolution and mechanical properties of Sr-modified Al-10Si alloys," Materials Science and Engineering, vol. 666, pp. 264-268, 2016.

[21] K. Wang, H. Y. Jiang, Y. W. Jia et al., "Nanoparticle-inhibited growth of primary aluminum in Al-10Si alloys," Acta Materialia, vol. 103, pp. 252-263, 2016.

[22] K. Wang, H. Y. Jiang, Y. X. Wang, Q. D. Wang, B. Ye, and W. J. Ding, "Microstructure and mechanical properties of hypoeutectic Al-Si composite reinforced with TiCN nanoparticles," Materials \& Design, vol. 95, pp. 545-554, 2016.

[23] K. Wang, H. Y. Jiang, Q. D. Wang, B. Ye, and W. J. Ding, "Nanoparticle-induced nucleation of eutectic silicon in hypoeutectic Al-Si alloy," Materials Characterization, vol. 117, pp. 41-46, 2016.

[24] H. Choi, M. Jones, H. Konishi, and X. Li, "Effect of combined addition of $\mathrm{Cu}$ and aluminum oxide nanoparticles on mechanical properties and microstructure of Al-7Si-0.3Mg alloy," Metallurgical and Materials Transactions A, vol. 43, no. 2, pp. 738-746, 2012.

[25] H. Choi and X. Li, "Refinement of primary Si and modification of eutectic Si for enhanced ductility of hypereutectic $\mathrm{Al}-20 \mathrm{Si}-4.5 \mathrm{Cu}$ alloy with addition of $\mathrm{Al} 2 \mathrm{O} 3$ nanoparticles," 
Journal of Materials Science, vol. 47, no. 7, pp. 3096-3102, 2012.

[26] H. Choi, H. Konishi, and X. Li, "Al2O3 nanoparticles induced simultaneous refinement and modification of primary and eutectic Si particles in hypereutectic Al-20Si alloy," Materials Science and Engineering, vol. 541, pp. 159-165, 2012.

[27] V. H. López, A. R. Kennedy, and R. García, "Flux-assisted spreading of an Al-7 wt\%Si alloy on TiC," Journal of Materials Science, vol. 45, no. 16, pp. 4321-4331, 2010.

[28] W. Liu, C. Cao, J. Xu, X. Wang, and X. Li, "Molten salt assisted solidification nanoprocessing of $\mathrm{Al}-\mathrm{TiC}$ nanocomposites," Materials Letters, vol. 185, pp. 392-395, 2016.

[29] K. M. Sree Manu, S. Arun Kumar, T. P. D. Rajan, M. Riyas Mohammed, and B. C. Pai, "Effect of alumina nanoparticle on strengthening of $\mathrm{Al}-\mathrm{Si}$ alloy through dendrite refinement, interfacial bonding and dislocation bowing," Journal of Alloys and Compounds, vol. 712, pp. 394-405, 2017.

[30] C. Kannan, R. Ramanujam, K. Venkatesan, N. V. Dheeraj, M. Raudhraa Sundaresh, and A. Vimal, "An investigation on the tribological characteristics of Al 7075 based single and hybrid nanocomposites," Materials Today Proceedings, vol. 5, no. 5, pp. 12837-12847, 2018, Part 2.

[31] M. Ahmadi and M. H. Siadati, "Synthesis, mechanical properties and wear behavior of hybrid $\mathrm{Al} /(\mathrm{TiO} 2+\mathrm{CuO})$ nanocomposites," Journal of Alloys and Compounds, vol. 769, pp. 713-724, 2018.

[32] S. Huo, L. Xie, J. Xiang, S. Pang, F. Hu, and U. Umer, "Atomic-level study on mechanical properties and strengthening mechanisms of $\mathrm{Al} / \mathrm{SiC}$ nano-composites," Applied Physics A, vol. 124, no. 2, p. 209, 2018.

[33] Y. Lu, D. Zhou, X. Li, J. Wang, W. Li, and Z. Bai, "Aluminum matrix composites reinforced with nano TiC particles: microstructure and wear behavior," Materiali in tehnologije, vol. 52, no. 5, pp. 673-678, 2018.

[34] J. Li, S. Lü, S. Wu, and Q. Gao, "Effects of ultrasonic vibration on microstructure and mechanical properties of nano-sized $\mathrm{SiC}$ particles reinforced $\mathrm{Al}-5 \mathrm{Cu}$ composites," Ultrasonics Sonochemistry, vol. 42, pp. 814-822, 2018.

[35] S.-s. Wu, D. Yuan, S.-l. Lü, K. Hu, and P. An, "Nano-SiCP particles distribution and mechanical properties of Al-matrix composites prepared by stir casting and ultrasonic treatment," China Foundry, vol. 15, no. 3, pp. 203-209, 2018.

[36] U. Pandey, R. Purohit, P. Agarwal, and S. Kumar Singh, "Study of fabrication, testing and characterization of Al/TiC metal matrix composites through different processing techniques," Materials Today Proceedings, vol. 5, no. 2, pp. 4106-4117, 2018, Part 1.

[37] T. Xu, G. Li, M. Xie et al., "Microstructure and mechanical properties of in-situ nano $\gamma$-Al2O3p/A356 aluminum matrix composite," Journal of Alloys and Compounds, vol. 787, pp. 72-85, 2019.

[38] M. C. Şenel, M. Gürbüz, and E. Koç, "Fabrication and characterization of synergistic Al-SiC-GNPs hybrid composites," Composites Part B: Engineering, vol. 154, pp. 1-9, 2018.

[39] Z. Guan, I. Hwang, and X. Li, "Highly concentrated WC reinforced Ag matrix nanocomposite manufactured by molten salt assisted stir casting," Procedia Manufacturing, vol. 26, pp. 146-151, 2018.

[40] F. Guo, W. Wang, W. Yu et al., "Enhanced nucleation and refinement of eutectic Si by high number-density nanoparticles in Al-10Si-0.5Sb alloys," Materials \& Design, vol. 117, pp. 382-389, 2017.
[41] J. N. Israelachvili and N. Jacob, Intermolecular and Surface Forces \| Adhesion and Wetting Phenomena, Elseiver, Amsterdam, Netherlands, pp. 415-467, 2011.

[42] X. Tosatti, "Hamaker constant calculations and surface melting of metals," Surface Science, vol. 251-252, pp. 641-644, 1991.

[43] V. Médout-Marère, S. Partyka, R. Dutartre, G. Chauveteau, and J. M. Douillard, "Surface heterogeneity of passively oxidized silicon carbide particles: vapor adsorption isotherms," Journal of Colloid and Interface Science, vol. 262, no. 2, pp. 309-320, 2003.

[44] S. B. Sinnott and E. C. Dickey, "Ceramic/metal interface structures and their relationship to atomic- and meso-scale properties," Materials Science and Engineering $R$, vol. 43, no. 1-2, pp. 1-59, 2003.

[45] L.-Y. Chen, J.-Q. Xu, H. Choi et al., "Processing and properties of magnesium containing a dense uniform dispersion of nanoparticles," Nature, vol. 528, no. 7583, pp. 539-543, 2015.

[46] E. Saiz, R. M. Cannon, and A. P. Tomsia, "Enhanced atomic transport at liquid metal/Al2O3 interfaces," Advanced $M a$ terials, vol. 47, no. 24, pp. 4209-4220, 1999.

[47] C. Cao, W. Liu, Z. Liu et al., "Scalable manufacturing of immiscible Al Bi alloy by self-assembled nanoparticles," Materials \& Design, vol. 146, pp. 163-171, 2018.

[48] X. Liu, S. Jia, and L. Nastac, "Ultrasonic cavitation-assisted molten metal processing of cast a356-nanocomposites," International Journal of Metalcasting, vol. 8, no. 3, pp. 51-58, 2014.

[49] Donthamsetty and N. Damera, "Ultrasonic cavitation assisted fabrication and characterization of A356 metal matrix nanocomposite reiforced with sic, B4C, CNTs," Scientific Information Database, vol. 2, pp. 27-34, 2009.

[50] J. Q. Xu, L. Y. Chen, H. Choi, and X. C. Li, "Theoretical study and pathways for nanoparticle capture during solidification of metal melt," Journal of Physics: Condensed Matter, vol. 24, no. 25, p. 255304, 2012.

[51] J. C. T. Kao, A. A. Golovin, and S. H. Davis, "Particle capture in binary solidification," Journal of Fluid Mechanics, vol. 625, pp. 299-320, 2009.

[52] L.-Y. Chen, J.-Q. Xu, H. Choi, H. Konishi, S. Jin, and X.-C. Li, "Rapid control of phase growth by nanoparticles," Nature Communications, vol. 5, no. 1, p. 3879, 2014.

[53] I. B. Ozsoy, G. Li, H. Choi, and H. Zhao, "Shape effects on nanoparticle engulfment for metal matrix nanocomposites," Journal of Crystal Growth, vol. 422, pp. 62-68, 2015.

[54] D. S. Zhou, J. Tang, F. Qiu, J. G. Wang, and Q. C. Jiang, "Effects of nano-TiCp on the microstructures and tensile properties of TiCp/Al-Cu composites," Materials Characterization, vol. 94, pp. 80-85, 2014.

[55] W. S. Tian, D. S. Zhou, F. Qiu, and Q. C. Jiang, "Superior tensile properties of in situ nano-sized $\mathrm{TiCp} / \mathrm{Al}-\mathrm{Cu}$ composites fabricated by reaction in melt method," Materials Science and Engineering, vol. 658, pp. 409-414, 2016.

[56] K. Nie, K. Deng, X. Wang, and K. Wu, "Characterization and strengthening mechanism of $\mathrm{SiC}$ nanoparticles reinforced magnesium matrix composite fabricated by ultrasonic vibration assisted squeeze casting," Journal of Materials Research, vol. 32, no. 13, pp. 2609-2620, 2017.

[57] A. Loucif, R. B. Figueiredo, T. Baudin, F. Brisset, R. Chemam, and T. G. Langdon, "Ultrafine grains and the Hall-Petch relationship in an Al-Mg-Si alloy processed by high-pressure torsion," Materials Science and Engineering, vol. 532, pp. 139-145, 2012. 
[58] Z. Zhang and D. Chen, "Consideration of Orowan strengthening effect in particulate-reinforced metal matrix nanocomposites: a model for predicting their yield strength," Scripta Materialia, vol. 54, no. 7, pp. 1321-1326, 2006.

[59] V. C. Nardone and K. M. Prewo, "On the strength of discontinuous silicon carbide reinforced aluminum composites," Scripta Metallurgica, vol. 20, no. 1, pp. 43-48, 1986.

[60] A. Sanaty-Zadeh, "Comparison between current models for the strength of particulate-reinforced metal matrix nanocomposites with emphasis on consideration of Hall-Petch effect," Materials Science and Engineering, vol. 531, pp. 112118, 2012.

[61] C. Goh, J. Wei, L. Lee, and M. Gupta, "Properties and deformation behaviour of $\mathrm{Mg}-\mathrm{Y} 2 \mathrm{O} 3$ nanocomposites," Acta Materialia, vol. 55, no. 15, pp. 5115-5121, 2007.

[62] Y. Zhang, S. Ji, and Z. Fan, "Improvement of mechanical properties of Al-Si alloy with effective grain refinement by insitu integrated Al2.2Ti1B-Mg refiner," Journal of Alloys and Compounds, vol. 710, pp. 166-171, 2017. 